\title{
Curriculum Architecture Based on Generalized Multimodal Information Fusion for ITO Training
}

\author{
Nan Ma, Hong Bao, Yun Zhai, Liyi Ma, and Wenfa Li
}

\begin{abstract}
The "one body two wings" for ITO talents training mechanism proposed by us has been proved its validity in teaching within Beijing Union University. To better support this mechanism, a generalized multimodal information fusion mechanism and the law of multi-measure training need demands were constructed, furthermore, a new curriculum system framework called the general multi-model information fusion system based training course system for ITO talents training, GMSIF, was established in this paper. The GMSIF consists of such three layer architecture as the theory layer, information fusion layer and curriculum presentation layer as well as curriculum evaluation model to realize its reconstruction and optimization. The GMSIF has been employed in the practice in teaching practice recently in Beijing Union University. Curriculum practice indicates that the new curriculum architecture has been powerfully supported the goal of "one body two wings" ITO talents training.
\end{abstract}

Index Terms - Generalized multimodal, information fusion, need demands, ITO talent training mechanism, curriculum system, service-outsourcing.

\section{INTRODUCTION}

The Chinese International Service Outsourcing Industry Development Plan jointly issued by the ministry of commerce of People's Republic of China and national development and reform commission points out that during the Twelfth five-year period, the annual average growth of Chinese offshore outsourcing business execution is about $40 \%$, and the total number will be up to $\$ 85$ billion RMB by 2015 , which accounts for the $28 \%$ proportion in the Chinese total service trade exports. Recently china strongly encourages the development of service outsourcing industry and continues to improve the policy and measures to develop service outsourcing in the specific cities. The government will continue to invest in service outsourcing for these cities for public service platform, especially to increase financial support for outsourcing information security and intellectual property protection. In this context, related fields such as

Manuscript received October 9, 2014; revised December 29, 2014. This research is partially supported by the innovation experimental zone of national service outsourcing talent training mode (high education (2009) Number 27), National Natural Science Foundation of China under grants 61300078 , and the project of new starting point of Beijing Union University under grants ZK10201312.

Nan Ma is with the College of Information Technology, Beijing Union University, No. 97 Beisihuan East Road, Chao Yang District, Beijing, P. R. China (e-mail: Wtmanan@buu.edu.cn).

Hong Bao, Liyi Ma, and Wenfa Li are with Beijing Union University, No. 97 Beisihuan East Road, Chao Yang District, Beijing, P. R. China (e-mail: baohong@buu.edu.cn).

Yun Zhai is with Chinese Academy of Governance, Beijing, 100089 China (e-mail: yunfei_2001_1@aliyun.com). computer science and technology, software engineering and others begin to vigorously train the service outsourcing talents in Chinese universities.

The paper is organized as follows. Section I summarizes the related research background. Section II presents analysis of ITO Personnel Training at home and aboard. Section III introduces the "One Body Two Wings" mechanism for ITO talents training in Beijing Union University. In Section IV, the proposed framework of the GMSIF is implemented. The paper ends with a summary and an outline of future research work on the application of GMSIF in dynamic and real teaching process using the proposed framework.

\section{CASE Analysis of ITO PeRsonnel Training AT Home AND ABOARD}

\section{A. ITO Talents Training in India}

In order to solve the bottleneck of ITO personnel training, colleges and universities at home and abroad have done related works for exploration and practice. Taking India as an example, it has been more than 20 years of development with large scale for the ITO business in India, and now India accounts for $61 \%$ of the global ITO market share. The industry output value of Indian software and information service had reached 60 billion dollars exporting to 105 countries and regions in the world, and the exports accounts for more than $20 \%$ of India's total exports [1]-[3].

\section{B. ITO Talents Training in China}

The ministry of education and the ministry of commerce of People's Republic of China issued concrete measures to vigorously develop the service outsourcing talent in computer science and technology fields. Currently, the ITO talents training in China mainly is implemented as follows: relying on national service outsourcing talent training areas; establishing specialized services outsourcing institute (or college) conducted ITO personnel training; relying on a professional, e.g., computer science and technology or software engineering for ITO talents.

For example, Hangzhou Normal University is a typical example relying on specialized college carry out training ITO Talents. Changsha University is a good instance relying on software engineering profession to conduct ITO personnel training. In addition, Xiamen University of Technology, Shanghai Jiao Tong University and Shandong Institute of Business and Technology all have their own characteristics both the profession plan and the curriculum architecture.

\section{The "One Body Two Wings" Mechanism for ITO \\ Talents Training in Beijing Union University}


Beijing Union University carries out ITO personnel training relying on the national service outsourcing talent training innovation experimental zone established in November 2009 empowered by the Ministry of Education. The experimental area meets needs of the development of the industry internationalization, especially growing demand for the offshore coupon technical service outsourcing industry, which learns from the European Union SFIA software talent standard [4], Japan ITSS skill standard [5], CMM and CMMI standard [4] as well as Chinese information technology services requirements proposed by ministry of industry and information technology of China [6].

Our experimental zone proposed the ITO talent training proposals for undergraduate curriculum system at the third Chinese trade and services Congress which made useful exploration and recommendations as well as put forward the " One Body Two Wings" training idea, i.e., the " One Body" takes the service ability as the core or the main body, and the " Two Wings" refer to the application ability of information technology and the professional ability of service outsourcing [7].

With the idea of " One Body Two Wings" , the leaning process are divided into such three stages as general training with industry awareness, triage training with workplace experience and professional training with work orientation. This idea helps students to develop good work ethic and pragmatism with an international vision, innovative spirit, sense of service and strong cross-cultural understanding. To enhance and develop the theoretical foundation of this idea for further study, in this paper, we proposed a curriculum theory framework based on generalized multimodal information fusion for ITO Training.

\section{THE THEORY FRAMEWORK OF GMSIF}

\section{A. Several Definitions}

Several definitions are given firstly as follows.

Definition 1. Multimodal refers to the interaction way between the human beings and external environment through multiple sensory modalities (e.g., visual, auditory and so on), and the multimodal teaching method highlights the collaborative participation with the body and brain via the multimodal way can't be separated with practical teaching process.

Definition 2. Information fusion theory comes from information science and mathematical science. Information fusion refers to analyze and comprehensively deal with the observation information come from multiple sensors such that people get required information to get the decision and estimation. In the process of information fusion, such contents are mainly included as the mathematics foundation for information fusion, classification and characteristics of the sources, the structure and function model of information fusion, state estimation fusion, recognition fusion for target, knowledge integration and performance evaluation.

Definition 3. General multi-model information fusion (GMIF) is an information fusion mechanism based on the information fusion theory and then meet needs of deepening its connotation, i.e., in the generalized teaching environment, we can achieve the fusion of cultivation ability, cultivation stage as well as the training goal.

In more details, the level of training goal orientation should be clear according to the compound cultivation target and training pattern in different personnel training process. Furthermore, training goal of the whole group or with varieties of personality should be set in accordance with professional skills and occupation needs.

In order to achieve goals above, we should establish a general multi-model information fusion system (GMIFS), and GMIFS must meet the requirements or functions as follows.

1) Information collection, i.e., the GMIFS can send the input information collected to multimodal information fusion system;

2) Feature extraction and fusion, i.e., the GMIFS can extract relevant features from the collected information and appropriately treat them;

3) The evaluation function for fusion, i.e., the GMIFS can evaluate the information and the characteristics collected, and then find out the main factors to optimize the curriculum system which can be optimized and reconstructed further.

4) Knowledge base updating, according to the assessment results and the optimization or reconstruction scheme for curriculum system, the knowledge base is updated dynamically with feedback.

Definition 4. Multiple-Measure Training-Needs-Position Based Law (MMTL). To achieve the goal of talent training, MMTL needs to reasonably set the training objective for different students with different personality in different process of personnel training. MMTL is specifically stated as follows.

Let mapping function $F=f(X, Y, Z)$, where $X=\left\{x_{1}, x_{2}\right\}, x_{1}=\{$ training objective for the whole students $\}=$ \{needs for the country, needs for the society, needs for the industry, individual needs, needs for the organization $\}, x_{2}=\{$ training objective for some student $\}=$ \{needs for the needs for the life\}, where $y_{m}$ is some specific training process;

$Z=\left\{z_{1}, z_{2}, z_{3}, \ldots z_{i}, \ldots z_{p-3}, z_{p-2}, z_{p-1}, z_{p}\right\}$ is training objective within "One Body Two Wings". We can correctly find out his training objective for the whole students and for some student for every tuple $(X, Y, Z)$ with the mapping function $F=f(X, Y, Z)$

\section{B. Framework of GMSIF}

The "One body two wings" mechanism, general multi-model information fusion and MMTL provide theoretical support for constructing the new curriculum system, as shown in Fig. 1.

As shown in Fig. 1, the theory framework of GMSIF is divided into such three layers as the basic theory layer, ability evaluation layer and the curriculum module layer, which are described and formulated as follows.

1) The basic theory layer is supported by the GMIF principle which contains "one body two wings" mechanism, the MMTL and the MMTL transformation matrix. Fig. 1 also shows clearly that the proposed 
GMSIF focuses on the realization of "one body two wings" for the ITO talent training goal and and the goal of the "four abilities", i.e., the basic quality and ability, ability for foreign language, ability in industry quality and ability in engineering practice.

2) Correct and scientific theory needs cultivating and revising through long time of evaluating the ability for training ITO talents. Data for evaluation comes from the results based on the multimodal information fusion, and then the evaluation results provide data and decision-making basis for the reconstruction and optimization of curriculum system. The evaluation model is described as follows.

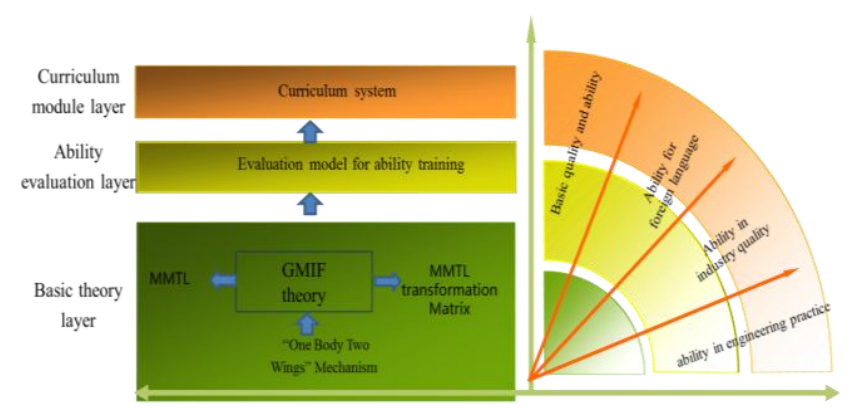

Fig. 1. Framework of GMSIF.

Let $\tau$ represent the training maturity of ITO talent, $\hbar, \pi$, $\partial$ and $\eta$ are formulated the basic quality and ability, ability for foreign language, ability in industry quality and ability in engineering practice respectively. And Let $\hbar^{\prime}$ and $\pi^{\prime}$ represent training objective for the whole students and training objective for some student. $\alpha, \beta, \gamma$ and $\mu$ represent indicators for these four type abilities, $\alpha^{\prime}$ and $\beta^{\prime}$ represent achievement indicators of $\hbar^{\prime}$ and $\pi^{\prime}$ respectively.

We can get

$$
\tau \propto(\alpha \hbar+\beta \pi+\gamma \partial+\mu \eta) \times\left(\alpha^{\prime} \hbar^{\prime}+\beta^{\prime} \pi^{\prime}\right)+\delta
$$

where $\alpha+\beta+\gamma+\mu=1 ; \alpha^{\prime}+\beta^{\prime}=1$.

In different learning stages we dynamically adjust values of $\alpha, \beta, \gamma$ and $\mu$ as well as $\alpha^{\prime}$ and $\beta^{\prime}$.

3) In the curriculum module layer, the curriculum are set according to the other layers, and take on three stages such as general training with industry awareness, triage training with workplace experience and professional training with work orientation, which are based on the target of training ITO talents to meet needs of "four abilities", to realize reconstructing and optimizing the basic courses, professional courses and quality courses.

\section{Implementation of GMSIF in Practice}

In teaching, we made in-depth understanding of business needs in close cooperation with Oracle (China) Software System Co., Ltd. and other enterprises. Based on the overall goal of curriculum for training ITO talents, we had been committed to curriculum innovation within the framework of multimodal information fusion theory to break barriers between different disciplines, and then we finally constructed the curriculum system based on the GMSIF, as shown in Fig. 2 (For length limited, we only choose some courses as an example).

\begin{tabular}{|c|c|c|c|c|c|c|c|}
\hline \multirow{2}{*}{\multicolumn{3}{|c|}{ Training project }} & \multicolumn{3}{|c|}{$\begin{array}{l}\text { training objective for the whole } \\
\text { students }\end{array}$} & \multirow{2}{*}{\begin{tabular}{|c|}
$\begin{array}{c}\text { training } \\
\text { objective } \\
\text { for some } \\
\text { student }\end{array}$ \\
$\begin{array}{c}\text { individual } \\
\text { needs }\end{array}$ \\
\end{tabular}} & \multirow[t]{2}{*}{ Rusult } \\
\hline & & & $\begin{array}{l}\text { needs for the } \\
\text { society }\end{array}$ & $\begin{array}{c}\text { needs for the } \\
\text { industry }\end{array}$ & $\begin{array}{c}\text { needs for the } \\
\text { business }\end{array}$ & & \\
\hline \multirow{16}{*}{$\begin{array}{c}\text { Profession } \\
\text { skill and } \\
\text { occupation } \\
\text { ability }\end{array}$} & \multirow{4}{*}{ The first year } & College English & $\begin{array}{l}\text { the second } \\
\text { objective }\end{array}$ & & $\begin{array}{l}\text { the second } \\
\text { objective }\end{array}$ & $\begin{array}{c}\text { objective } \\
\text { with } \\
\text { characteristics }\end{array}$ & $\begin{array}{l}\text { the second } \\
\text { objective }\end{array}$ \\
\hline & & Higher mathematics & & $\underset{\text { main }}{\text { objective }}$ & $\underset{\text { main }}{\text { objective }}$ & \begin{tabular}{|c|} 
objective \\
with \\
characteristics
\end{tabular} & main objective \\
\hline & & Program design basis & $\underset{\text { main }}{\text { objective }}$ & & & $\begin{array}{c}\text { objective } \\
\text { with } \\
\text { characteristics }\end{array}$ & main objective \\
\hline & & $\begin{array}{l}\text { Humanities and social science } \\
\text { courses }\end{array}$ & & $\begin{array}{c}\text { main } \\
\text { objective }\end{array}$ & $\begin{array}{c}\text { main } \\
\text { objective }\end{array}$ & & main objective \\
\hline & \multirow{4}{*}{ The second year } & $\begin{array}{l}\text { Information service project } \\
\text { management }\end{array}$ & & & $\begin{array}{l}\text { the second } \\
\text { objective }\end{array}$ & $\begin{array}{c}\text { objective } \\
\text { with } \\
\text { characteristics }\end{array}$ & $\begin{array}{l}\text { the second } \\
\text { objective }\end{array}$ \\
\hline & & operating system management & & $\begin{array}{c}\text { main } \\
\text { objective }\end{array}$ & $\begin{array}{c}\text { main } \\
\text { objective }\end{array}$ & $\begin{array}{c}\text { objective } \\
\text { with } \\
\text { characteristics }\end{array}$ & $\begin{array}{c}\text { main } \\
\text { objective }\end{array}$ \\
\hline & & Database principle & & & $\begin{array}{l}\text { the second } \\
\text { objective }\end{array}$ & & $\begin{array}{l}\text { the second } \\
\text { objective }\end{array}$ \\
\hline & & service oriented modeling analysis & & $\begin{array}{c}\text { main } \\
\text { objective }\end{array}$ & $\begin{array}{c}\text { main } \\
\text { objective }\end{array}$ & $\left|\begin{array}{c}\text { objective } \\
\text { wih } \\
\text { characteristics }\end{array}\right|$ & main objective \\
\hline & \multirow{4}{*}{ The third year } & $\begin{array}{l}\text { Fundamentals of advanced } \\
\text { language }\end{array}$ & & $\begin{array}{c}\text { main } \\
\text { objective }\end{array}$ & $\begin{array}{c}\text { main } \\
\text { objective }\end{array}$ & $\begin{array}{c}\text { main } \\
\text { objective }\end{array}$ & main objective \\
\hline & & Web platform programming & & $\begin{array}{c}\text { main } \\
\text { objective }\end{array}$ & $\begin{array}{c}\text { main } \\
\text { objective }\end{array}$ & $\begin{array}{c}\text { main } \\
\text { objective }\end{array}$ & main objective \\
\hline & & Mobile platform programming & & $\begin{array}{c}\text { main } \\
\text { objective }\end{array}$ & $\begin{array}{c}\text { main } \\
\text { objective }\end{array}$ & $\begin{array}{c}\text { main } \\
\text { objective }\end{array}$ & main objective \\
\hline & & Software service English/Japanese & & $\begin{array}{c}\text { main } \\
\text { objective }\end{array}$ & $\begin{array}{c}\text { main } \\
\text { objective }\end{array}$ & $\begin{array}{c}\text { main } \\
\text { objective }\end{array}$ & main objective \\
\hline & \multirow{4}{*}{ The forth year } & IT system architecture & & $\begin{array}{c}\text { main } \\
\text { objective }\end{array}$ & $\begin{array}{c}\text { main } \\
\text { objective }\end{array}$ & $\begin{array}{c}\text { main } \\
\text { objective }\end{array}$ & main objective \\
\hline & & knowledge of the industry & & $\begin{array}{c}\text { the second } \\
\text { objective }\end{array}$ & $\begin{array}{l}\text { the second } \\
\text { objective }\end{array}$ & $\begin{array}{c}\text { objective } \\
\text { with } \\
\text { characteristics }\end{array}$ & $\begin{array}{l}\text { the second } \\
\text { objective }\end{array}$ \\
\hline & & Plan and goal management & & & & $\begin{array}{c}\text { objective } \\
\text { with } \\
\text { characteristics }\end{array}$ & $\begin{array}{c}\text { objective } \\
\text { with } \\
\text { characteristics }\end{array}$ \\
\hline & & Software testing skills & & $\underset{\text { main }}{\text { objective }}$ & $\underset{\text { main }}{\text { objective }}$ & $\begin{array}{c}\text { objective } \\
\text { with } \\
\text { characteristics }\end{array}$ & main objective \\
\hline
\end{tabular}

Fig. 2. Practice of GMSIF. 
In recent years, the GMSIF has been applied to the the information technology service outsourcing talent training for undergraduate in Beijing Union University. And we have developed more than ten new curriculums. Practical teaching results in the innovation experimental zone take on gratifying achievements, where students actively participate in various competitions and achieved good results, winning rate over $90 \%$.

Moreover, just as our efforts and exploration in the GMSIF, the innovation experimental zone has been widely recognized by the society and more and more organizations, and we were gloriously awarded the honor as one of the ten best service outsourcing educational institutions in china in 2012.

\section{CONCLUSIONS AND FUTURE DIRECTIONS}

The paper discussed relevant work, and proposes a novel curriculum theory framework, based on the general multi-model information fusion. The follow-up results in teaching practice show that the proposed GMSIF is very effective. The future work will concern the use of the GMSIF in a context of more widely practice in other universities and complex circumstances.

\section{ACKNOWLEDGMENT}

The authors would like to thank Ye Yang and Chen $\mathrm{Yu}$, staff of Oracle (China) Software System Co., Ltd., for their constructive suggestions.

\section{REFERENCES}

[1] H. Bao, T. Peng, L. Y. Sun, and Y. X. Zhang, "Research information service outsourcing industry personnel occupational skills standards," Computer Science, vol. 37, no. 9A, 2010.

[2] M. Sramana, "The coming death of Indian outsourcing," Forbes Magazine December 21, 2010.

[3] The evolution of BPO in India. (September 10, 2011). Price Water House Coopers Report. [Online]. Available: www.pwc.com/images/tech/BPO in India.pdf.

[4] H. Bao, H. L. Zhou, and H. Shen, "Service outsourcing undergraduate talents training mode reform and innovation - in Beijing Union University," China Higher Education Research, vol. 7, 2013.

[5] K. Caputo, CMM Implementation Guide, U.K.: Addison-Wesley Educational Publishers Inc., 2008.

[6] Ministry of industry and information technology, "Chinese information technology service standards (ITSS)," White Paper, 2010

[7] The Skills Framework for the Information Age (SFIA). (October 8 , 2014). [Online]. Available: http://www.sfia-online.org/

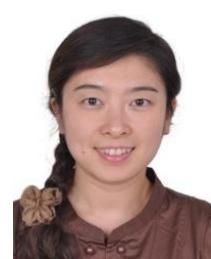

Nan Ma was born in Beijing, China. She received her $\mathrm{Ph} . \mathrm{D}$. degree in computer application from University of Science and Technology Beijing, China and M.S degree in Beijing University of Post and Telecommunication. She is now a research staff member at the College of Information Technology in Beijing Union University, China. Her current research interests include intelligent system, and data mining (knowledge discovery).

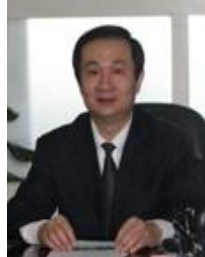

Hong Bao was born in Beijing, China. He received his Ph.D. degree in computer science from school of computer and information technology from Beijing Jiaotong University Beijing, China and M.S. degree in information technology from Liverpool University, U.K. He is now a professor of Beijing Union University, Beijing, China. His current research interests include image processing, visual perception and distributed system.

Yun Zhai was born in Shandong province, China in 1979. He is a Ph.D. He obtained his Ph.D. degree in 2012 from University of Science and Technology Beijing. His current research interests include knowledge discovery and e-government intelligence. 